\title{
CYP7B1 Mutations in French-Canadian Hereditary Spastic Paraplegia Subjects
}

\author{
Anne Noreau, Patrick A. Dion, Anna Szuto, Annie Levert, Pascale Thibodeau, Bernard Brais, \\ Nicolas Dupré, Marie-France Rioux, Guy A. Rouleau
}

Can. J. Neurol. Sci. 2012; 39: 91-94

Hereditary spastic paraplegia (HSP), also called StrümpellLorrain disease, refers to progressive motor neurodegenerative disorders characterized by lower limb spasticity and weakness. This group of diseases has been shown to include very heterogeneous clinical manifestation and various modes of inheritance (dominant, recessive and X-linked) have been reported. Hereditary spastic paraplegia are classified as pure or complicated forms. Cases with pure forms only present lower limb spasticity but complicated forms have additional neurological features such as cerebellar ataxia, intellectual disabilities, dementia, thin corpus callosum, and/or visual dysfunction.

To date, over 48 spastic paraplegia loci including 20 genes have been identified. In 1994, one of these loci, SPG5A, was mapped to chromosome $8 \mathrm{q} 21.3$ and deemed to contain a gene underlying a pure-autosomal recessive form of HSP (MIM\#270800) ${ }^{1}$. Many HSP families have been mapped to this particular locus and the causative gene was finally identified in 2008. Mutations in Cytochrome P450, family 7, subfamily B polypeptide 1 ( $C Y P 7 B 1)$ gene were then found to underlie this particular disorder; homozygous mutations were originally identified in a consanguineous English family ${ }^{2}$. CYP7B1 extends over $\sim 220 \mathrm{~Kb}$ gene and contain six exons that encode for an evolutionarily conserved steroid metabolizing enzyme, cytochrome P450. This particular enzyme is widely expressed in many tissues, with the highest mRNA levels found in the liver and the brain. Containing 506 amino-acid, this enzyme catalyzes the $6 \alpha-7 \alpha$ hydroxylation of several endogenous substrates such as: dehydroepiandrosterone, pregnenolone, oxysterols, 25-and 27-hydroxycholestrol. In the liver, $C Y P 7 B 1$ is implicated in the synthesis of bile salt that regulate bile flow and indirectly the excretion of metabolites (e.g. porphyrins arising from heme breakdown). Interestingly, mutations in the $C Y P 7 B 1$ gene are also known to cause liver failure in children. Additional roles for $C Y P 7 B 1$ were described in the metabolism of oestrogen receptor ligands and in immunoglobulin production ${ }^{3}$. The exact role of $C Y P 7 B 1$ in the brain is unknown, other than its link to HSP. The main goal of our study was to determine if CYP7B1 mutations could explain disease in some of our HSP patients.

\section{METHODS}

Patient samples. Protocols for the recruitment were approved by the Ethics Committee of the Centre Hospitalier de l'Université de Montréal. Patients gave informed consent, after which clinical information and blood was collected. Recruitment has been ongoing over the last twenty years and the laboratory recruited over 1077 participants, particularly 366 affected within the families. All affected participants had spastic gait, lower limb spasticity, weakness and hypereflexia. None of the participant in this study had mutations in the HSP causative genes SPASTIN (SPG4), ATLASTIN (SPG3A), STRUMPELLIN (SPG8) and SPATACSIN (SPG11). Amongst the 86 samples selected: 22 appeared to have a recessive inheritance, 31 a dominant inheritance and 33 no family history for HSP. Genomic DNA was extracted from $30 \mathrm{ml}$ blood using the Puregene DNA kit (Gentra Puregene Blood kit for $30 \mathrm{ml}$ blood: RBC Lysis Solution, RNAse A Solution and Reagents); following the manufacturer's protocol (Gentra System, USA). A control cohort of 192 healthy individuals found to be free of any neurodegenerative disorder was used.

PCR amplification and sequencing. UCSC ExonPrimer (http://genome.ucsc.edu/) was used to design seven sets of primers for the amplification of the six coding exons and their respective flanking splice junctions. The complete list of primers used and the PCR conditions can be found in supplementary data. Amplification products were sequenced at the Genome Quebec Innovation Centre (Montréal, Québec, Canada) using a 3730XL DNAnalyzer (Applied Biosystems, Foster City, California). Mutation surveyor (v.3.10, SoftGenetics, State College, Pennsylvania) was used for mutation detection analysis with the NM_004820 reference sequence. Mutations were confirmed by re-amplifying the fragment and sequencing its two strands (forward and reverse). Following the identification of a case showing a definite mutation, DNA from relatives was amplified, when available, to see if the mutation segregated with the disease. Mutation frequencies in cases and controls were compared using Fisher's exact test, where $\mathrm{P}<0.05$ was considered statistically significant.

From the Center of Excellence in Neuroscience of Université de Montréal (CENUM) (AN, PAD, AS, AL, PT, BB, GAR), Centre de Recherche du Centre Hospitalier de l'Université de Montréal (CRCHUM); Université de Montréal, Department of Pathology and Cellular Biology (PAD); University of Montreal, Faculty of Medicine, Department of Medicine (GAR); Research Center (GAR), CHU Sainte-Justine, Montreal; Faculty of Medicine (ND), Laval University, Department of Neurological Sciences, CHA-Enfant-Jésus, Quebec; Centre Hospitalier Universitaire de Sherbrooke (CHUS) (MFR), Fleurimont, Quebec, Canada.

Received May 6, 2011. Final Revisions Submitted July 20, 2011.

Correspondence to: Guy A. Rouleau, CHUM Research Centre, 2099, Alexandre DeSeve Street, Room Y-3633, Montreal, Quebec, H2L 2W5, Canada. 


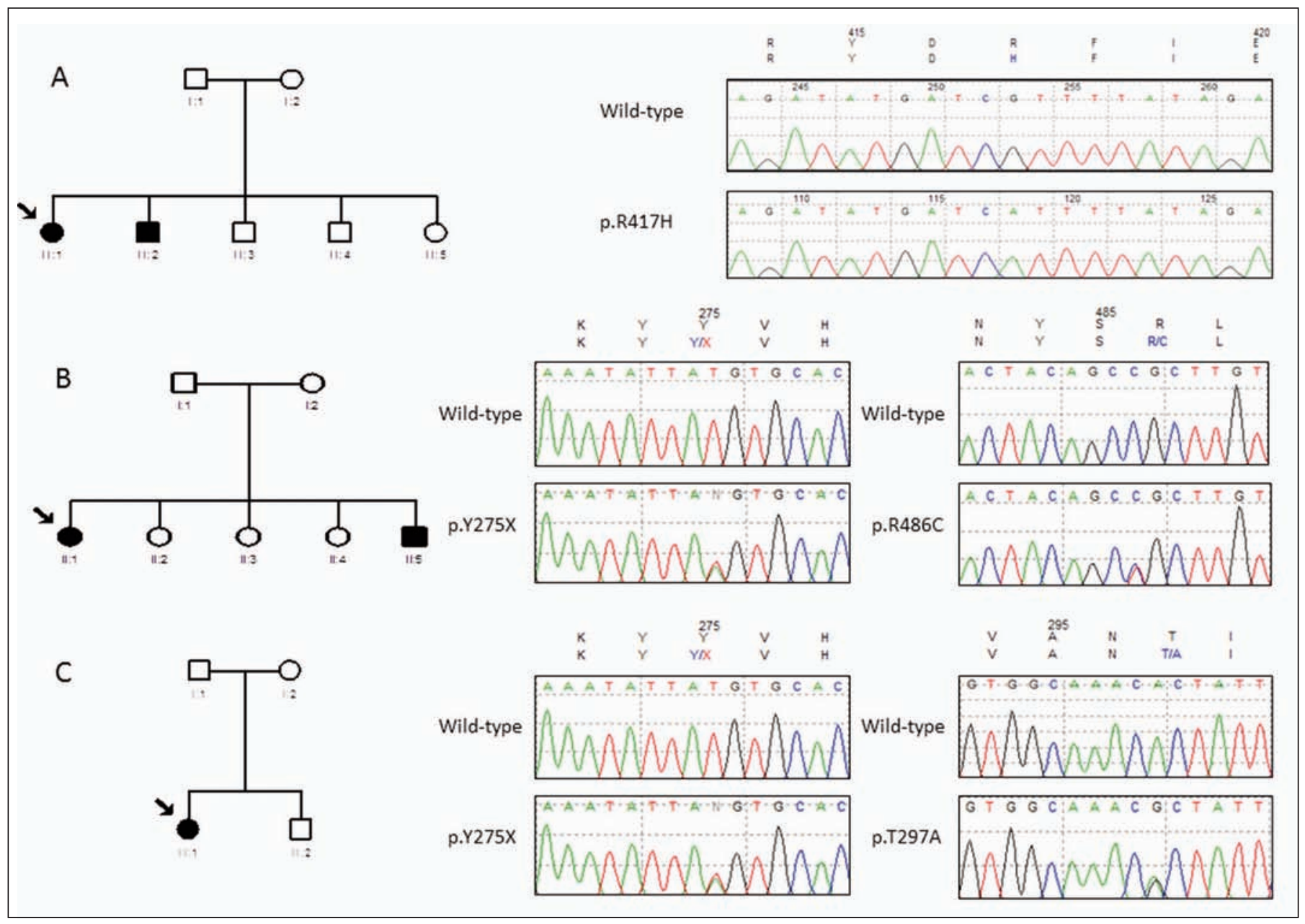

Figure: Pedigrees and sequences traces.

Table: Mutation detection analysis in $C Y P 7 B 1$ gene in our HSP cohort and relatives

\begin{tabular}{|c|c|c|c|c|c|c|c|}
\hline Family & $\begin{array}{c}\text { Mode of } \\
\text { inheritance }\end{array}$ & Individual & $\begin{array}{c}\text { Family } \\
\text { member }\end{array}$ & Clinical status & Mutation & $\begin{array}{l}\text { Amino-Acid } \\
\text { change }\end{array}$ & Zygocity \\
\hline \multirow{3}{*}{ A } & \multirow{3}{*}{$\begin{array}{l}\text { Autosomal } \\
\text { recessive }\end{array}$} & II:1 & Proband & Affected & c. $1450 \mathrm{G}>\mathrm{A}$ & p.R417H & Homozygote \\
\hline & & II:3 & brother & Unaffected & c. $1450 \mathrm{G}>\mathrm{A}$ & p.R417H & Heterozygote \\
\hline & & $\mathrm{I}: 2$ & mother & Obligate carrier & c. $1450 \mathrm{G}>\mathrm{A}$ & p.R417H & Heterozygote \\
\hline \multirow{4}{*}{$\mathrm{B}$} & \multirow{4}{*}{$\begin{array}{l}\text { Autosomal } \\
\text { recessive }\end{array}$} & \multirow{2}{*}{ II:1 } & \multirow{2}{*}{ Proband } & \multirow{2}{*}{ Affected } & c. $825 \mathrm{~T}>\mathrm{A}$ & p.Y275X & Heterozygote \\
\hline & & & & & c. $1456 \mathrm{C}>\mathrm{T}$ & p.R486C & Heterozygote \\
\hline & & \multirow{2}{*}{ II:5 } & \multirow{2}{*}{ Brother } & \multirow{2}{*}{ Affected } & c. $825 \mathrm{~T}>\mathrm{A}$ & p.Y275X & Heterozygote \\
\hline & & & & & c. $1456 \mathrm{C}>\mathrm{T}$ & p.R486C & Heterozygote \\
\hline \multirow{5}{*}{$\mathrm{C}$} & \multirow{5}{*}{ Sporadic } & \multirow{2}{*}{ II: 1} & \multirow{2}{*}{ Proband } & \multirow{2}{*}{ Affected } & c. $825 \mathrm{~T}>\mathrm{A}$ & p.Y275X & Heterozygote \\
\hline & & & & & c. $889 \mathrm{~A}>\mathrm{G}$ & p.T297A & Heterozygote \\
\hline & & II:2 & Brother & Unaffected & no mutation & no change & Wild-type \\
\hline & & \multirow{2}{*}{$\mathrm{I}: 2$} & \multirow{2}{*}{ Mother } & \multirow{2}{*}{ Unaffected } & c. $825 \mathrm{~T}>\mathrm{A}$ & p.Y275X & Heterozygote \\
\hline & & & & & no mutation & no change & Wild-type \\
\hline
\end{tabular}




\section{Results}

An overall sequencing success rate of $99.7 \%$ was obtained in our HSP cohort. The Table lists all the mutations identified in this study. We first identified a homozygous mutation (c.1450G $>$ A) in the sixth exon of $C Y P 7 B 1$ that change a perfectly conserved amino-acid (p.R417H). The family of this French Canadian case (Figure, Family A) has a recessive inheritance pattern. The unaffected mother and one unaffected brother were found to be heterozygote carriers for the c.1450G $>$ A mutation; DNA from other family members was not available. The proband had definite HSP with disease onset at the age of seven, and some sensory involvement and seizures. A homozygous c.1450G >A mutation was previously reported in a Tunisian consanguineous family $^{2}$ and as a compound heterozygous state in a French sporadic case ${ }^{4}$.

The second case was an unrelated French Canadian family (Figure, Family B), both the HSP proband and her affected brother had compound heterozygous mutations in $C Y P 7 B 1$. The proband was seen by a neurologist who made the diagnosis of HSP or spastic-ataxia with marked sensory involvement. Disease onset was at 22 years-of-age, but brisk tendons reflexes had been previously observed. Both the proband and her brother had an allele with a c.825T $>$ A change that translates to a protein truncating nonsense mutation (p.Y275X). Homozygous c.825T $>$ A mutations were previously reported in a Portuguese sporadic HSP case in whom additional features of optic atrophy were noted ${ }^{4}$. The second mutated allele of $C Y P 7 B 1$ was found to be a c.1456C $>\mathrm{T}$ change that creates a missense mutation p.R486C in the last exon. This c.1456C $>\mathrm{T}$ mutation was reported in a consanguineous Portuguese family ${ }^{4}$. None of the parents or the three other unaffected siblings were available for gene screening.

The third case (Figure, Family C) was again from a French Canadian family with a diagnosis of HSP associated with a mild sensory deficit. The age of onset was as early as four years old and no other family member was affected, though one uncle and one aunt, on her mother's side, had severe multiple sclerosis. The screening of $C Y P 7 B 1$ revealed compound heterozygous mutations. One of the mutated alleles had the p.Y275X mutation described in family $\mathrm{B}$, and the other a missense mutation c.889A $>\mathrm{G}$ in the fourth exon that produce a p.T297A amino-acid change, that was already described by Goizet et $\mathrm{al}^{4}$. The mother was tested for mutations in $C Y P 7 B 1$ and found to carry only the truncating mutation. None of these two mutations were observed in the unaffected brother, thus confirming the segregation of mutations for the disease. Unfortunately, the father was not available for mutation detection analysis.

\section{Discussion}

We report here another $C Y P 7 B 1$ heterozygote mutation, c. $971 \mathrm{G}>\mathrm{A}$ (p.R324H), in five families with recessive inheritance and four families with dominant inheritance. This variant was listed in dbSNP (rs59035258) and has an average heterozygosity of $2.8 \%$. A comparative analysis of its mutation frequencies in our 86 HSP cases and 178 control individuals indicated these were respectively $9.30 \%$ and 5.06\%; a non-significant difference when using a Fisher test ( $\mathrm{p}$-value $=0.2882$; OR $=1.83$ ). Moreover, additional family members were screened, when available, and there was no segregation of this variant with the disease. This mutation was considered by Schüle et al as a phenotype modifier of complex HSP phenotypes; ${ }^{5}$ we have no data to support this contention.

All the mutations identified in this study were previously reported in SPG5A families, though not in the same compound heterozygous combinations. Our results suggest that mutation in CYP7B1 may be responsible for $9.1 \%$ of the autosomal recessive cases of HSP. This mutation frequency is similar to the $10.8 \%$ of autosomal recessive families reported in a meta-analysis by Arnoldi et $\mathrm{al}^{6}$. We can also say that the phenotypes observed were similar to HSP subjects already described. It is interesting to note that our three patients harbouring mutations in $C Y P 7 B 1$ had reduced sensation in their lower extremities. This sign was also found in familial cases described by Arnoldi et al. ${ }^{6}$ One of our 33 seemingly sporadic cases has a CYP7B1 mutation, suggesting that it may be worthwhile screening this gene in such cases, especially if they have prominent sensory signs and symptoms. For clinicians following French-Canadian HSP patients, it may be pertinent to request a mutational screening analysis of $C Y P 7 B 1$ as the number of mutations identified in patients from this population is substantial. The number of French-Canadian HSP cases investigated may be too small for a clearly significant prevalence of SPG5 cases to be observed. For now, the easiest and cheapest way to proceed is by Sanger sequencing. In the near future, it will be possible to use diagnostic tools that will be developed, to do screening of all the genes involved in HSP. This will ensure a rapid clinical diagnosis and will hopefully help to treat patients according to the causative gene involved.

\section{ACKNOWLEDGEMENTS}

G.A.R. holds the Canada Research Chair and a Jeanne-et-J.Louis-Levesque Chair for the Genetics of Brain Diseases and A.N. holds a Doctoral Award - Frederick Banting and Charles Best Graduate Scholarship by the Canadian Institutes of Health Research (CIHR).

\section{REFERENCES}

1. Hentati A, Pericak-Vance MA, Hung WY, et al. Linkage of 'pure' autosomal recessive familial spastic paraplegia to chromosome 8 markers and evidence of genetic locus heterogeneity. Hum Mol Genet. 1994;3(8):1263-7.

2. Tsaousidou MK, Ouahchi K, Warner TT, et al. Sequence alterations within CYP7B1 implicate defective cholesterol homeostasis in motor-neuron degeneration. Am J Hum Genet. 2008;82(2): 510-5.

3. Stiles AR, McDonald JG, Bauman DR, Russell DW. CYP7B1: one cytochrome $\mathrm{P} 450$, two human genetic diseases, and multiple physiological functions. J Biol Chem. 2009;284(42):28485-9.

4. Goizet C, Boukhris A, Durr A, et al. CYP7B1 mutations in pure and complex forms of hereditary spastic paraplegia type 5. Brain. 2009;132(Pt 6):1589-600

5. Schule R, Brandt E, Karle KN, et al. Analysis of CYP7B1 in nonconsanguineous cases of hereditary spastic paraplegia. Neurogenetics. 2009;10(2):97-104.

6. Arnoldi A, Crimella C, Tenderini E, et al. Clinical phenotype variability in patients with hereditary spastic paraplegia type 5 associated with CYP7B1 mutations. Clin Genet. 2011;

See following page for supplemental data 


\section{Supplemental Data: Primer sequences and PCR conditions for CYP7B1 gene}

\begin{tabular}{|c|c|c|c|c|c|c|}
\hline & Exon covered & Amino-acids & Primer Sequence & PCR condition & $\begin{array}{l}\text { PCR Master- } \\
\text { Mix }\end{array}$ & $\begin{array}{c}\text { Excepted PCR } \\
\text { product size } \\
\text { (bp) }\end{array}$ \\
\hline CYP7BI_ExI_F & \multirow{2}{*}{ Exon 1} & \multirow{2}{*}{1 to 41} & ATTCCTGTCTGCGCTGC & \multirow{2}{*}{ A } & \multirow{2}{*}{1} & \multirow{2}{*}{391} \\
\hline CYP7B1_Ex1_R & & & CCCGCAGCAAGTTCTGAC & & & \\
\hline CYP7B1_Ex2_F & \multirow{2}{*}{ Exon 2} & \multirow{2}{*}{41 to 87} & AAGTTGCTCACCAGAAGTTATGC & \multirow{2}{*}{ B } & \multirow{2}{*}{2} & \multirow{2}{*}{582} \\
\hline CYP7B1_Ex2_R & & & ATGGCTGGAAAGAAGGGTTC & & & \\
\hline CYP7B1_Ex3_1F & \multirow{2}{*}{ Exon 3-start } & \multirow{2}{*}{$87-210$} & TCCACCATCTTTCAAAGGAAAC & \multirow{2}{*}{ B } & \multirow{2}{*}{2} & \multirow{2}{*}{622} \\
\hline CYP7B1_Ex3_IR & & & GCTCAATGGGTATGTTGGATAC & & & \\
\hline CYP7B1_Ex3_2F & \multirow{2}{*}{ Exon 3- end } & \multirow{2}{*}{$180-283$} & TCTTGGAAAGCATGATGCAG & \multirow{2}{*}{ B } & \multirow{2}{*}{2} & \multirow{2}{*}{640} \\
\hline CYP7B1_Ex3_2R & & & GATAAGAGGAGTAAATGCAGCTTAG & & & \\
\hline CYP7B1_Ex4_F & \multirow{2}{*}{ Exon 4} & \multirow{2}{*}{ 284-353 } & CTCATTAGCATGCACTGATCC & \multirow{2}{*}{ B } & \multirow{2}{*}{2} & \multirow{2}{*}{501} \\
\hline CYP7B1_Ex4_R & & & TGCAATGAGAGTATCTACGGC & & & \\
\hline CYP7B1_Ex5_F & \multirow{2}{*}{ Exon 5} & \multirow{2}{*}{$353-411$} & TCCCTCTTGGTGCTCAATG & \multirow{2}{*}{ B } & \multirow{2}{*}{2} & \multirow{2}{*}{438} \\
\hline CYP7B1_Ex5_R & & & CCATCAAGCTGCCTCAAAC & & & \\
\hline CYP7B1_Ex6_F & \multirow{2}{*}{ Exon 6} & \multirow{2}{*}{$412-507$} & TGCTTAATTTGCACTCAGCC & \multirow{2}{*}{ A } & \multirow{2}{*}{1} & \\
\hline CYP7B1_Ex6_R & & & TTTGTGACTAAGGACAAACTGGAC & & & 591 \\
\hline PCR condition : A & & & & PCR condition & : B & \\
\hline $96 \mathrm{C}$ & $2 \mathrm{~min}$ & & & $95 \mathrm{C}$ & $5 \mathrm{~min}$ & \\
\hline $95 \mathrm{C}$ & $9 \mathrm{~min}$ & & & $\overline{94 C}$ & $20 \mathrm{sec}$ & \\
\hline $95 \mathrm{C}$ & $\operatorname{lmin}$ & & & $70 \mathrm{C}$ & $20 \mathrm{sec}$ & 17 cycles $(-1.0 \mathrm{C} / \mathrm{cycle})$ \\
\hline $65 \mathrm{C}$ & $30 \mathrm{sec}$ & 11 cycles $(-1.0 \mathrm{C}$ & ycle) & $72 \mathrm{C}$ & $30 \mathrm{sec}$ & - \\
\hline $72 \mathrm{C}$ & $1 \mathrm{~min}$ & & & $\overline{94 C}$ & $20 \mathrm{sec}$ & \\
\hline $94 \mathrm{C}$ & $\operatorname{lmin}$ & & & $54 \mathrm{C}$ & $20 \mathrm{sec}$ & 25 cycles \\
\hline $57 \mathrm{C}$ & $30 \mathrm{sec}$ & 31 cycles & & $72 \mathrm{C}$ & $30 \mathrm{sec}$ & \\
\hline $72 \mathrm{C}$ & $1 \mathrm{~min}$ & & & $72 \mathrm{C}$ & $5 \mathrm{~min}$ & \\
\hline
\end{tabular}

Master Mix : 1

\begin{tabular}{|l|c|c|c|}
\hline DNA & $1.0 \mathrm{ng} / \mathrm{uL}$ & $5 \mathrm{ng}$ & $\mathbf{5 . 0 u L}$ \\
\hline $\mathrm{H}_{2} \mathrm{O}$ & - & - & $1,51 \mathrm{uL}$ \\
\hline $\mathrm{MgCl}_{2}$ & $25 \mathrm{mM}$ & $0.5 \mathrm{mM}$ & $0,3 \mathrm{uL}$ \\
\hline Buffer Qiagen & $10 \mathrm{X}$ & $1 \mathrm{X}$ & $1.5 \mathrm{uL}$ \\
\hline $\mathrm{dNTP}$ deaza & $1,25 \mathrm{mM}$ & $200 \mathrm{uM}$ & $2,4 \mathrm{uL}$ \\
\hline HotStarTaq Qiagen & $5 \mathrm{U} / \mathrm{uL}$ & $0.75 \mathrm{U}$ & $0.15 \mathrm{uL}$ \\
\hline Primer F & $10 \mathrm{uM}$ & $0.38 \mathrm{uM}$ & $0.57 \mathrm{uL}$ \\
\hline Primer $\mathrm{R}$ & $10 \mathrm{uM}$ & $0.38 \mathrm{uM}$ & $0.57 \mathrm{uL}$ \\
\hline Betaine & $5 \mathrm{X}$ & $1 \mathrm{X}$ & $3.0 \mathrm{uL}$ \\
\hline total volume & & & $\mathbf{1 5 , 0 u \mathrm { u }}$ \\
\hline
\end{tabular}

Master Mix : 2

\begin{tabular}{|l|c|c|c|}
\hline DNA & $1.0 \mathrm{ng} / \mathrm{uL}$ & $5 \mathrm{ng}$ & $5.0 \mathrm{uL}$ \\
\hline $\mathrm{H}_{2} \mathrm{O}$ & - & - & $2.34 \mathrm{uL}$ \\
\hline $\mathrm{MgCl}_{2}$ & $25 \mathrm{mM}$ & $1.5 \mathrm{mM}$ & $0.9 \mathrm{uL}$ \\
\hline $\mathrm{Buffer}$ & $10 \mathrm{X}$ & $1 \mathrm{X}$ & $1.5 \mathrm{uL}$ \\
\hline $\mathrm{dNTP}$ & $2,5 \mathrm{mM}$ & $167 \mathrm{uM}$ & $1.0 \mathrm{uL}$ \\
\hline AmpliTaqGold & $5 \mathrm{U} / \mathrm{uL}$ & $0.6 \mathrm{U}$ & $0.12 \mathrm{uL}$ \\
\hline Primer F & $10 \mathrm{uM}$ & $0.38 \mathrm{uM}$ & $0.57 \mathrm{uL}$ \\
\hline Primer $\mathrm{R}$ & $10 \mathrm{uM}$ & $0.38 \mathrm{uM}$ & $0.57 \mathrm{uL}$ \\
\hline Betaine & $5 \mathrm{X}$ & $1 \mathrm{X}$ & $3.0 \mathrm{uL}$ \\
\hline total volume & & & $\mathbf{1 5 , 0 u l}$ \\
\hline
\end{tabular}

